\title{
Reduction of Acute Anterior Shoulder Dislocation Using Intraarticular Lidocaine(IAL) and Stimson's Technique
}

\author{
Thapa BB ${ }^{1}$, Chand $\mathrm{P}^{1}$, Kayastha ${ }^{1}$, Rana $\mathrm{S}^{1}, \mathrm{KC}$ NB${ }^{1}$, Joshi $\mathrm{A}^{1}$, Singh $\mathrm{BP}^{1}$, Shah $\mathrm{BC}^{1}, \mathrm{KC} \mathrm{BR}^{1}$ \\ ${ }^{1}$ Shree Birendra Army Hospital, Chhauni, Kathmandu, Nepal
}

\begin{abstract}
Introduction: Shoulder dislocation is common injury requiring urgent reduction. For the reason that patient is not nill orally and anesthetists are not available, reduction under intra venous anaesthesia is not possible. This study was aimed to evaluate the effectiveness of intraarticular lidocaine and stimson's technique of shoulder dislocation, which could be performed without anesthetist and irrespective of nill orally status.

Methods: A prospective observational study was performed from December 2009 to December 2010. Under all antiseptic precautions $20 \mathrm{ml}$ of Lidocaine was injected intraarticularly and reduction was performed by Stimson's technique. Visual Analogue Score, time for reduction and failure to reduction by this technique was recorded.

Results: Out of 27 dislocations 22 were successfully reduced and remaining required added scapular manipulation. The mean VAS scor was $2.3 \pm 1.26$ and the mean time of reduction was $17.96 \pm 1.9$ minutes.

Conclusion: Stimson's method with Intraarticular Lidocaine is effective, safe, less costly and can be performed in periphery where anesthetist and monitoring facilities are not available.
\end{abstract}

Key words: Anterior dislocation, Stimson's technique

\section{Introduction}

Most dislocations occurres in teenagers and young adults and are rare after 45 years of age ${ }^{2}$. Shoulder joint dislocations constitute about $50 \%$ of all dislocations. The incidence of traumatic dislocation is increasing in our country because of industrialization leading to more road traffic accidents. The dislocation must be reduced as soon as possible for two reasons. First, to minimize ongoing damage to the joint and its surrounding structures. Second, to reduce pain and suffering.

Presently, shoulder dislocations are reduced under IV anesthesia, which requires anesthetist and other supportive equipments to administer IV anesthesia. Our country is lacking not only instruments and equipments for IV anesthesia but also anesthetists. In various districts of our country we donot have anesthetist so reduction is to be performed by orthopedic surgeon with substantial risk. Significant central nervous system and respiratory depression can occur with intravenous analgesia and sedation; so close monitoring is essential. Nausea, vomiting and lethargy may occur; requiring prolonged observation. Intra-articular lignocaine $(I A L)$ has been advocated for manual reduction of acute anterior shoulder dislocation providing analgesia and subsequent muscle relaxation to the patients. This method is advantageous because it does not require intravenous anesthesia and thereby close monitoring. So only a short emergency stay is required resulting in fewer complications. The procedure is also cost effective ${ }^{3,4}$.

There are various methods of reduction of acute anterior shoulder dislocation. In our study we used a Stimson's technique, needing no assistant.

Address for Correspondence:

Name: Dr. Bishnu Babu Thapa

E-mail: bishnubthapa1@hotmail.com

Ph. №.: 9841251030 


\section{Methods}

This was a prospective discriptive study of to evaluate the outcome of reduction of acute anterior shoulder dislocation with the use of intraarticular lidocaine and Stimson's technique. All patients aged 16-70 years who attended Shree Birendra Army Hospital with acute anterior shoulder dislocation within 5 days were included in the study. Patients with multiple trauma, fracture, recurrent dislocation, pregnancy, and associated co morbid condition were excluded from the study.

All patient's detailed history and clinical examination were taken. Special tests like Duga's test, and Hemilton's ruler test were performed and neurovascular status noted. Dislocation was confirmed clinically and radiographically. A detailed performa was filled up.

Patients were placed in supine position on table during administration of intraarticular lidocaine. Later patient was placed in prone position during reduction. The procedure was explained to each patient. The acromion and humeral head were palpated and approximate location of the axillary nerve was noted where it split the deltoid muscle laterally. An area $2 \mathrm{~cm}$. inferior and directly lateral to the acromion, in the lateral sulcus formed by the absent of humeral head, was prepared with povidone iodine soaked swabs. Then a $20 \mathrm{ml}$ syringe was introduced directing it slightly caudad into the shoulder joint. Aspiration of the joint was first performed to remove fluid if present resulting from a torn capsule or labrum. $20 \mathrm{ml}$ of $1 \%$ lidocaine was drawn into the $20 \mathrm{ml}$ syringe. The lidocaine was injected over a period of approximately 30 seconds $^{5}$. The patient was allowed to relax in the supine position for about 5 minutes before the reduction manoeuvre was attempted.

The patient was then placed prone on the stretcher with the affected arm hanging down and $4.5 \mathrm{~kg}$ of traction was applied by strapping it onto the arm. While in prone position the patient was asked to rate pain on VAS scale of $0-10^{4}$.

When reduction occurred, patient tended to become comfortable and often could tell exactly when the shoulder relocated. Reduction was confirmed by palpation of reduced humeral head. After the shoulder was reduced, sling was applied.

If not reduced within 25 minutes, scapular manipulation was performed in the same position ${ }^{4}$. If reduction was not achieved even after the scapular manipulation, reduction was performed by Kocher's method under intravenous sedation and analgesia.

During the study period (Sept.2008 to sept.2010) a total of 32 acute anterior shoulder dislocation patients were encountered in Emergency department of our hospital.Twenty seven were included in our study.

In our study, age of the patients ranged form16 to $60 y$ rs with mean of 29.59 yrs. Majority of patients were in the age group of 21 to $40 \mathrm{yrs}$. Males were involved mostly.

Table 1: Demographic data

\begin{tabular}{|c|c|}
\hline $\begin{array}{ll}\text { Sex } & \\
& \text { Male } \\
& \text { Female }\end{array}$ & $\begin{array}{l}24 \\
3\end{array}$ \\
\hline Side & \\
\hline Right & 17 \\
\hline Left & 10 \\
\hline Age & 29.59 yrs \\
\hline Age distribution & \\
\hline$<20$ years & 5 \\
\hline $20-40$ years & 19 \\
\hline$>40$ years & 3 \\
\hline Mode of Injury & \\
\hline Fall & 13 \\
\hline RTA & 8 \\
\hline Physical assault & 3 \\
\hline Timing of presentation & \\
\hline Within 24 hrs & 22 \\
\hline After $24 \mathrm{hrs}$ & 5 \\
\hline VAS & $2.3 \pm 1.26$ \\
\hline Reduction time & $17.96 \pm 1.9$ \\
\hline Success rate & \\
\hline Stimson's technique & 22 \\
\hline $\begin{array}{l}\text { Additional technique } \\
\text { required }\end{array}$ & 5 \\
\hline
\end{tabular}

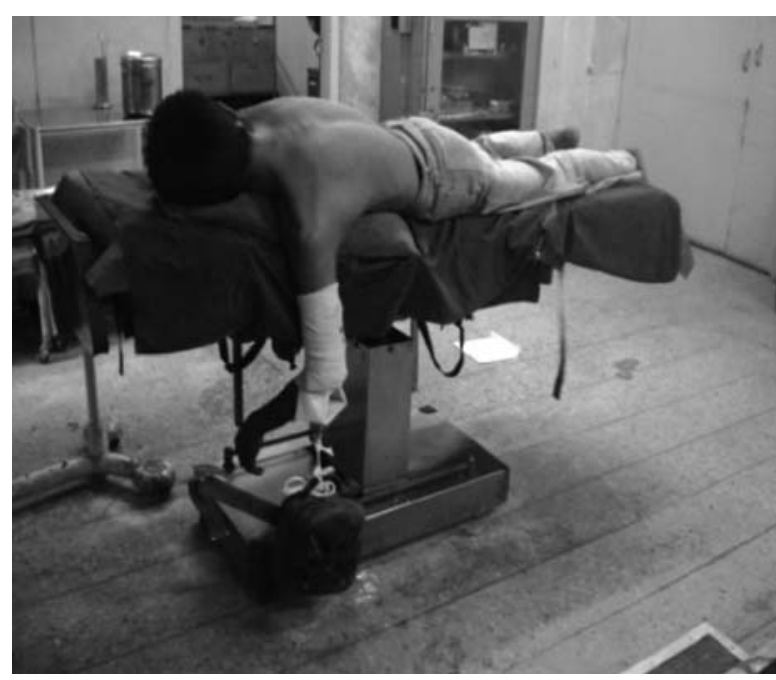




\section{Discussion}

Many techniques have been described for reducing anterior shoulder dislocations. The ideal reduction should be easily performed, effective,relatively painless, safe, and allow for expeditious discharge of the patient ${ }^{3}$. Parental analgesics and sedations were used for reduction of shoulder dislocation which required anesthetist and equipment. Our study showed that intraarticular lidocaine with stimson's reduction method were very effective can be performed by orthopedic surgeon and doesnot need anesthetist to involved with minimal complication.

The age of the patients at the time of initial dislocation has major effect on the incidence of redislocation. A total of $95 \%$ of primary traumatic dislocations recurred in teenagers and young.

Involvement of right shoulder dislocation is more. But Danial E Matthews' study showed,that left side were involved more ${ }^{3}$. This may be due to difference in the modality of trauma. Injury due to fall from height is more common in our part of the world as compared to road traffic accidents in the developed world.

During reduction, pain was measured in visual analogue score(VAS) ranging from $1-10^{6}$. The mean VAS were 2.30; most falling in 1 to 3 . Some time VAS is more so there is difficulty in reduction and there fore will require Intravenous analgesia. This is one of the complication of IAL. In our study one patient had VAS 4 and two had VAS 6.

In our study out of 27 cases, there were 5 failures with Stimson's method. They required scapular manipulation to achieve reduction. Most of the failure cases were presented after 24 hours of injury. In our study 22 patients came to the hospital within 24 hours of injury. Complication have been reported with Kocher's method, like near total rupture of pectoralis major tendon from its humeral attachment and iatrogenic fracture of humerus ${ }^{7,8}$. But, No such complication has been reported with Stimson's method.

Patient's satisfaction with IAL has been good, although some patients with prior shoulder reductions done under sedation may prefer the same treatment ${ }^{9}$. Some patients may be fearful of sedation. IAL provides another possible option in such cases. IAL may be used in adjunct to sedation, allowing lower doses of sedative medications.

\section{Conclusion}

Intraarticular lidocaine represents a useful alternative to facilitate the reduction of anterior shoulder dislocation.From this study we came to the conclusion that reduction of anterior shoulder dislocation with IAL and Stimson's method is effective, safe,less costly and can be performed in periphery where anesthetists and monitoring facilities are not available.

\section{References}

1. Louis S, Dadid JW, Selvadurai N. Apley's system of orthopaedics and feactures, Mosby, 8th edition, 581.

2. Samuel L T. Orthopardics principles and their applications. Vol II 4th edition, 936.

3. Matthews DE, Roberts T. intraarticular lidocaine vs IV analgesia for the reduction of acute anterior shoulder dislocation. university of Mississippipe. The American journal of sports medicine.1995;23(1):5458.

4. Miller S, Cleeman E, Auerbach J, Flatow E. Comparsion of intraarticular lidocaine and intravenous sedation for reduction of shoulder dislocation. JBJS. 2002;84-A:2135.

5. Steven JS, Lee VT. Intraarticular lidocaine for the reduction of posterior shoulder dislocation. Can $\mathrm{j}$ emerg med 2005;7(6);423-426.

6. Acupuncture in medicine. Measuring pain,Adrian White ;1998:Vol-16,No.2.

7. Pimpalnerkar $A$ et.al. An unusual complication of Kocher's manoeuvre. BMJ 2004; 329;1472-1473.

8. RiazA. latrogenic fracture of humerus, complication of diagnostic error in a shoulder dislocation. Journal of medical case reports. 2007 July.

9. Kosnik J. Shamsa F. Raphael E. Anesthetic methods for reduction of acute shoulder dislocations: a prospective randomized study comparing intraarticular lidocaine with intravenous analgesia and esdation. Am J Emerg Med. 1999 oct; 17(6): 566-70. 